\title{
Conflict grows over breast cancer strategy
}

San Francisco. Last week's annual meeting of the American Association for the Advancement of Science (AAAS) became the site of the latest skirmish in an increasingly bitter conflict between US scientists working on the prevention and treatment of breast cancer and activists who claim that government-backed efforts in the field are misguided.

The clash provided further evidence of the extent to which, in the absence of scientific consensus on the causes of cancer, groups that feel more emphasis should be placed on rapidly selecting and eliminating environmental causes are determined to make themselves heard.

"We must not allow the scientific community to tell us that what we need is more research," says Samuel Epstein, a professor of medicine at the University of Illinois at Chicago, speaking at a panel session on breast cancer research policy in the US.

Epstein, who claims that sufficient data exist to justify the banning of a number of allegedly carcinogenic substances, used the occasion to launch an attack on the policies of the National Cancer Institute (NCI), the main research funding body in the field, which is part of the National Institutes of Health.

But he and other session panel members were challenged by Mina Bissell, a biologist at Lawrence Berkeley Laboratory in California. Bissell said that Epstein had inadequate data to back up some of his claims, and - to cheers from half of the 300 people in the hall - criticized the AAAS for arranging a session which had ended up as "an attack on all of science".

"If you don't build your bridges with the help of scientists and engineers, you will fall into the ocean," Bissell told the meeting as she was crowded away from the microphone by the two co-chairs of the session, Janice Kirsch of the health care group Kaiser Permanente at Hayward, California and Nancy Evans of the lobby group Breast Cancer Action. Order was then briefly lost as supporters of the panellists, seated at the front of the hall, exchanged insults with the sceptical scientists at the back.

During these exchanges, Epstein said he

\section{How a meeting of minds can spell trouble}

Clashes of culture can undermine international joint research ventures, researchers from Ohio State University and Lehigh University told last week's meeting of the AAAS. Foreign research laboratories also suffer from a mismatch of values and perceptions fostered by different societies.

A study of 235 engineers and managers at 40 US-Japanese joint ventures showed that participants from the two countries disagreed on preferred ways of communicating, of improving production and of measuring performance, said Robert Mason, of the Center for the Management of Science and Technology at Case Western Reserve University in Ohio.

According to Japanese engineers, 'quality' meant the best that could be achieved at the moment, based on state-of-the-art knowledge, and 'effectiveness' was demonstrated by levels of creativity and innovation. US workers said high quality meant meeting specifications, and talking to customers was the best measure of effectiveness.

Mason said such disagreements often remain unspoken, and can lead to conflict. He recommended that participants in joint projects be trained to look for hidden assumptions, and to define their terms.

Joseph Cheng, associate professor of international business and management at Ohio State University, said companies can enhance the performance of an overseas laboratory or joint venture by designing an appropriate corporate culture. For example, a "technology transfer" laboratory organ- ized to adapt a product for use in a foreign market would benefit from strong influence from corporate headquarters.

Cheng added that a laboratory director from the home office, who built up strong reporting relationships and made frequent visits to headquarters, would help strengthen the influence of the corporation. But a laboratory intended to develop products for local markets would operate better with strong local influence and less corporate attention.

Theodore Schlie, associate professor of technology management at Lehigh Univer-

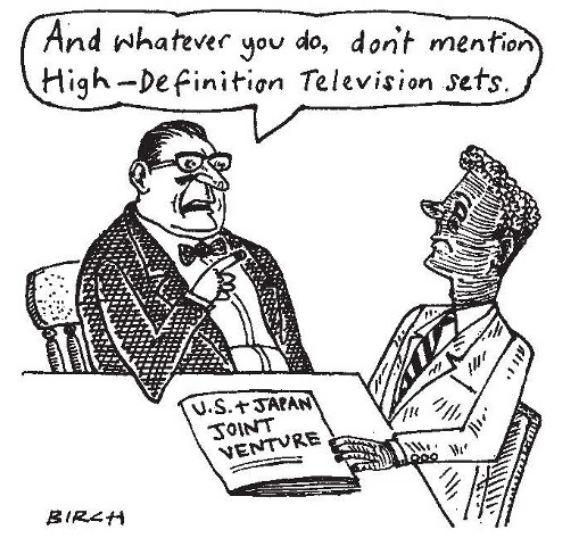
between headquarters and the foreign laboratory was vital. Temporary foreign assignments, electronic communication and "meetings, meetings, meetings" all contributed to this goal. sity in Pennsylvania, said communication was not being critical of individual researchers, but argued that "the science community is held hostage" to the political process that directs its work. Earlier, he had delivered a barrage of criticism of the American Cancer Society (ACS), the NCI and other government agencies. He accused the NCI of spending only 3 per cent of its $\$ 1.9$ billion annual research budget on identifying "avoidable carcinogens", while pumping money into research on the effects of a fatty diet, evidence for which was "tenuous".

Epstein said that the expanding use of Xray mammography to screen women for breast cancer in the US was "reckless if not criminal". He attacked as "flawed" a recent study by the ACS and the Food and Drug Administration (FDA) which concluded that there was "almost no connection" between hair dyes and cancer, and he proposed a link between breast cancer and the consumption of milk from BST-supplemented cows, due to allegedly high levels of insulin growth factor (IGF-1) in the milk.

The breast cancer session also included presentations linking the disease with medical X-rays, pesticides, postmenopausal hormone therapy and exposure to various chemicals that function as xenoestrogens.

Lobbies such as Breast Cancer Action and the Cancer Prevention Coalition, which Epstein chairs, say they have learned much from the AIDS activist movement, and their determination to be heard looks certain to raise the profile of public debate on cancer research policy.

Colin Macilwain

\section{Genome project 'has opened Pandora's box'}

The Human Genome Project has raised ethical issues that no-one knows how to deal with, according to several speakers addressing a discussion on genetic research into sexual orientation during the AAAS meeting.

Dean Hamer of the NCI, who last July published results linking genetics and homosexuality that triggered intense debate, told the meeting that "in dealing with human sexuality, we have a lot more to fear from ignorance than from my work".

According to opinion polls, many parents, given the choice, would abort fetuses carrying a range of behavioural and physical characteristics. Hamer said that any form of genetic screening based on his work "would be wrong", but he did not specify how it could be prevented.

Donald Gabard, of the department of physical therapy at Chapman College, California, said the whole human genome project had "opened a Pandora's box" that neither researchers or doctors could be trusted to close.

c. $\mathbf{M}$. 